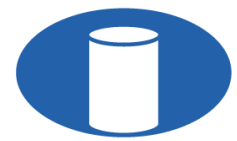

IBRACON Structures and Materials Journal

Revista IBRACON de Estruturas e Materiais

IBRACON

ISSN 1983-4195

ismj.org

ORIGINAL ARTICLE

\title{
Evaluation of formulations for predicting the shear strength of concrete filled circular holes in steel plates
}

\section{Avaliação de fórmulas para obtenção da capacidade resistente dos furos circulares em chapa de aço preenchidos com concreto}

\author{
Larice Gomes Justino Miranda ${ }^{\mathrm{a}}$ \\ Otávio Prates Aguiar ${ }^{\mathrm{a}}$ (D) \\ Paulo Estevão Carvalho Silvério ${ }^{\mathrm{a}}$ (i) \\ Rodrigo Barreto Caldas ${ }^{\mathrm{a}}$ (i)
}

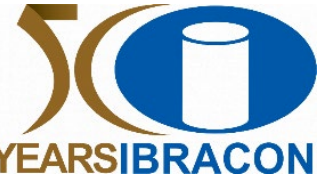

${ }^{a}$ Universidade Federal de Minas Gerais - UFMG, Departamento de Engenharia de Estruturas, Belo Horizonte, MG, Brasil

Received 21 October 2020

Accepted 02 March 2021

\begin{abstract}
Since the development of perforated plate shear connectors, different formulations have been proposed to predict their shear strength. Most of these formulations were derived from standard push-tests on multiple concrete filled holes (CFH) specimens simulating specific steel-concrete composite beam applications. Aiming at a more general application of these connectors in composite structures and the understanding of the physical and geometric parameters that influence their shear strength, the present work evaluated the use of 12 different formulations to predict 92 test results of single-hole specimens extracted from the literature. Such tests were chosen because the single-hole configuration allows better isolation of the connection behavior which facilitates comparative analysis. The predictions were statistically evaluated, and it was considered that the best formulations were those that showed lower scatter of data and a correction factor closer to one. Also, it was investigated if the individual terms that constitute the formulations adequately describe or show relation to the mechanics that govern the connection. It was verified that the best statistically rated formulations were also the ones showing clearer relation to the connector mechanical behavior. Among the evaluated formulations, three were significantly better than the others for strength prediction, however, it was noted that they can be further improved by considering the influence of concrete confinement and plate thickness on the hole's strength.
\end{abstract}

Keywords: composite structures, shear connectors, concrete filled circular holes in steel plates, push tests, statistical evaluation.

Resumo: Desde o desenvolvimento de conectores de cisalhamento em chapa contínua com furos circulares, diferentes formulações foram propostas para o cálculo da capacidade resistente dos mesmos. A maior parte dessas formulações foi desenvolvida com base no ensaio push-out padrão de protótipos com múltiplos furos simulando a aplicação desses conectores em vigas mistas de aço e concreto. Visando a aplicação mais geral desses conectores em estruturas mistas e o entendimento dos parâmetros físicos e geométricos que influenciam em sua capacidade resistente, avaliou-se, no presente trabalho, a aplicação de 12 dessas formulações a 92 resultados de ensaio. Esses ensaios extraídos da literatura têm em comum o fato de apresentarem apenas um furo solicitado. Escolheram-se ensaios com essa característica por permitirem isolar melhor o comportamento da conexão, facilitando análises comparativas. Os resultados extraídos foram avaliados estatisticamente, sendo consideradas as melhores formulações aquelas que apresentaram menor dispersão de dados e fator de correção próximo à unidade. Além disso, foi investigado se os termos individuais que constituem as formulações descrevem adequadamente ou mostram relação com a mecânica que rege a conexão. Verificou-se que as formulações mais bem avaliadas estatisticamente foram também as que apresentaram uma relação mais clara com o comportamento mecânico do conector. Dentre as formulações avaliadas, três se mostraram significativamente melhores que as demais para previsão da capacidade resistente, contudo, observou-se que ainda é possível aprimorá-las se levada em consideração a influência do confinamento e espessura da chapa na capacidade resistente do furo.

Palavras-chave: estruturas mistas, conector de cisalhamento, chapa contínua com furos circulares, ensaios de cisalhamento direto, avaliação estatística.

Corresponding author: Larice Gomes Justino Miranda. E-mail: laricejustino@yahoo.com.br

Financial support: None.

Conflict of interest: Nothing to declare.

Data Availability: The data that support the findings of this study are available from the corresponding author, LGJM, upon reasonable request. 
How to cite: L. G. J. Miranda, O. P. Aguiar, P. E. C. Silvério, and R. B. Caldas, "Evaluation of formulations for predicting the shear strength of concrete filled circular holes in steel plates," Rev. IBRACON Estrut. Mater., vol. 15, no. 4, e15401, 2022, https://doi.org/10.1590/S198341952022000400001

\section{INTRODUCTION}

Concrete filled circular holes in steel plates (CFH) with or without a transverse rebar are applied frequently in composite connections. Initially, the CFH were observed only in composite beams, as a constituent part of shear connectors, called Perfobond [1]. However, several other applications have emerged over the years (Figure 1) [2]-[5].

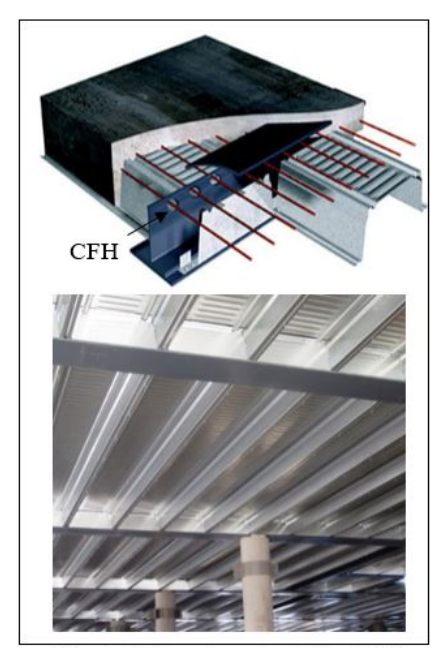

(a) CoSFB - ArcelorMittal [2]

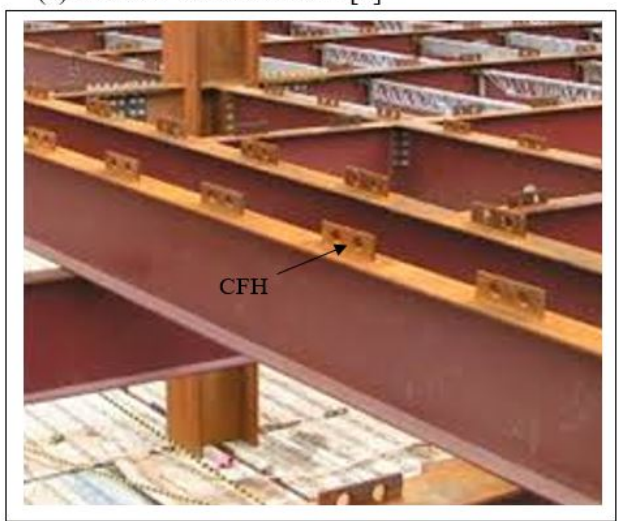

(c) Vianna et al. [4]
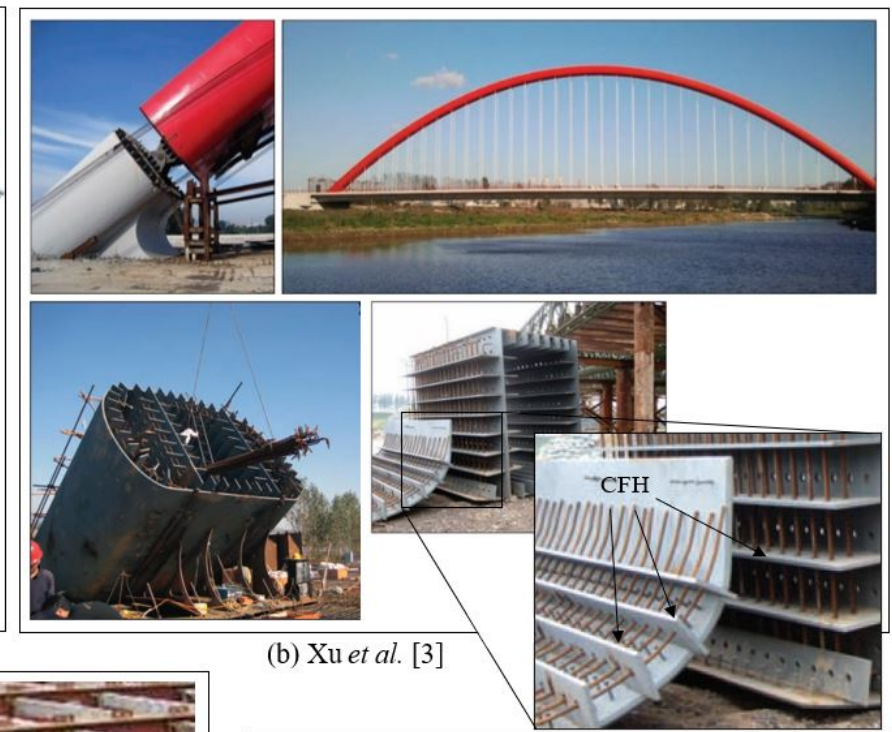

(b) Xu et al. [3]

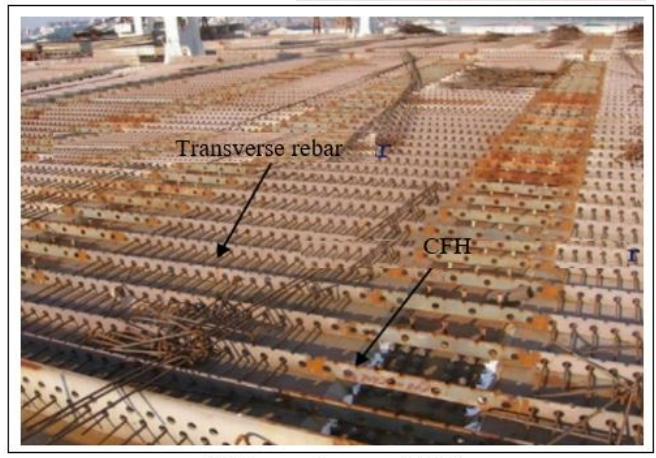

(d) Peng-zhen et al. [5]

Figure 1. Examples of CFH applications: a) slim-floor beams; b) composite bridge transitions; c) composite beam (original conception of Perfobond); d) composite bridge decks.

Although there are several applications of CFH in civil construction, it is noted that a large part of the research that involve these elements was dedicated to studying not the CFH itself, but some structural arrangement (most often Perfobond connectors in composite beams) in which the $\mathrm{CFH}$ is a constituent part. Therefore, although there are several formulations designed to predict the shear strength of connections composed by $\mathrm{CFH}$, it is observed that part of them present high errors if applied to predict the resistance of a single $\mathrm{CFH}$. This is due to the fact that these formulations are mostly associated with failure modes that are specific of the studied structural arrangement and not of the CFH itself.

Therefore, this work proposes to study the CFH regardless of various applications already proposed for this element, through an investigation to identify, among the main equations of literature, those that best express the behavior of $\mathrm{CFH}$ and can predict its shear strength with greater precision. 
In this investigation it was evaluated the use of 12 different formulations to predict 92 test results of single CFH. The predictions were statistically compared based on Annex D of EN 1990: 2002 [6] and the best formulations were those that showed lower scatter of data, a correction factor closer to one and their constituent terms better adjusted to the connector's mechanical behavior.

Tests with single-hole specimens were chosen because, by focusing the analysis on one hole, that is, the aspect common to any application or variation of $\mathrm{CFH}$, it is possible to better isolate the fundamental mechanisms that govern the connection and the geometric and material parameters that influence them, thus reducing the number of parameters that influence the test results and facilitating the comparison among the 12 formulations. In doing so, it was possible to dissociate the behavior of the hole from other variables such as the end bearing resistance (contact between the edge of the steel plate and the concrete), that occur in some applications of the connector, and the distance between consecutive holes, which relates to the overlapping of stress fields in the concrete [7], as shown in Figure 2.

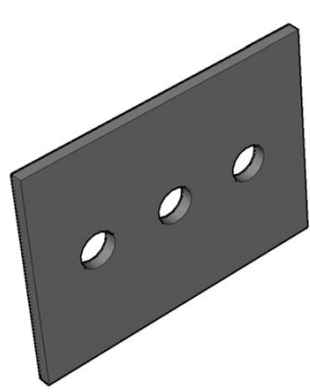

CFH rib

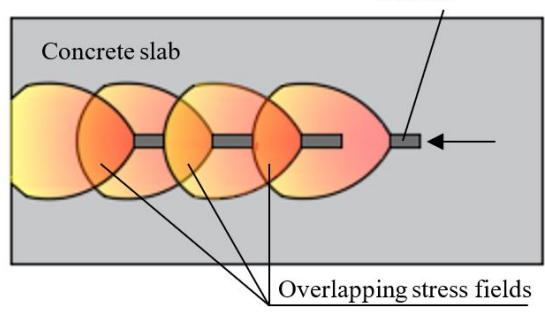

(a)
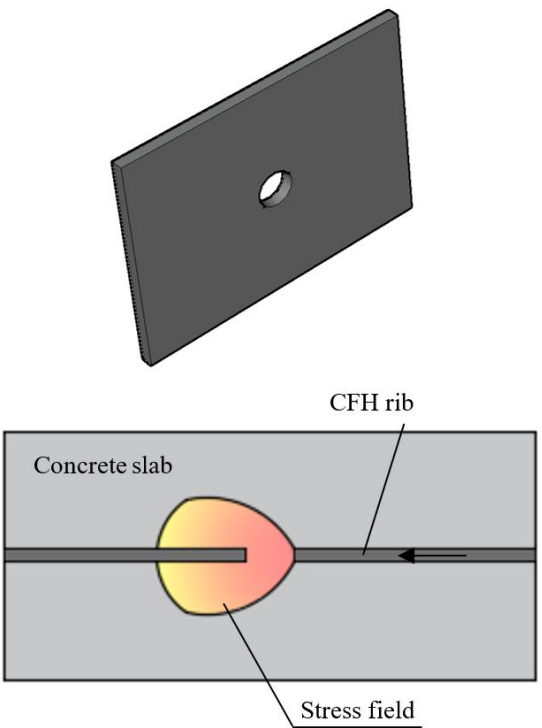

(b)

Figure 2. Representation of stress fields in a concrete slab for a) CFH rib with end bearing resistance and multiple holes and b) continuous $\mathrm{CFH}$ rib with a single hole.

It was considered in this work that if a formulation, though conceived for a given $\mathrm{CFH}$ application with specific geometric settings, can predict with enough accuracy the strength of a single hole, it may be considered suitable to express the fundamental mechanisms that govern the connection. Therefore, with some adaptations, it may be possible to extrapolate it to predict the strength of any application or variation of $\mathrm{CFH}$, for example, ensuring an adequate distance between the centers of the holes, greater than 2.25 times the diameter of the hole [7]. However, if the formulation fails to predict the strength of a single hole, it can be concluded that it is not properly based on the physics that governs the connection and can not be extrapolated for CFH applications that differ from the one for which it was proposed.

\section{LITERATURE REVIEW}

\subsection{Shear tests on CFH}

\subsubsection{General}

Since the development of the $\mathrm{CFH}$, several researches have been conducted for assessing its behavior in different structural application, mainly through push-test tests, standardized in Annex B of EN 1994-1-1:2004 [8]. The standard 
push test specimen consists of two small concrete slabs connected to a steel profile by the shear connectors. A vertical compression load is applied to the top of the steel profile, which slides in relation to the slabs. By measuring both the applied load and the vertical relative displacement between steel and concrete, the connector's load $\times$ slip curve is obtained.

$\mathrm{Su}$ et al. [9] states that the standard push test, also referred as push-out test, brings a deviation angle between the direction of resultant shear force of connector and the direction of applied force (Figure 3), which induces a pull-out force component in the connector and an increase in the friction between the steel profile and the slab. The deviation angle magnitude varies according to the specimen dimensions, which is one of the reasons why different results are often observed among tests of similar connectors by different researchers. Moreover, push-out tests are mostly directed to shear connectors in shallow applications, i.e., where the connectors are near the concrete surface, as the standard specimen is designed to simulate the interaction of steel beams with typical concrete slabs.

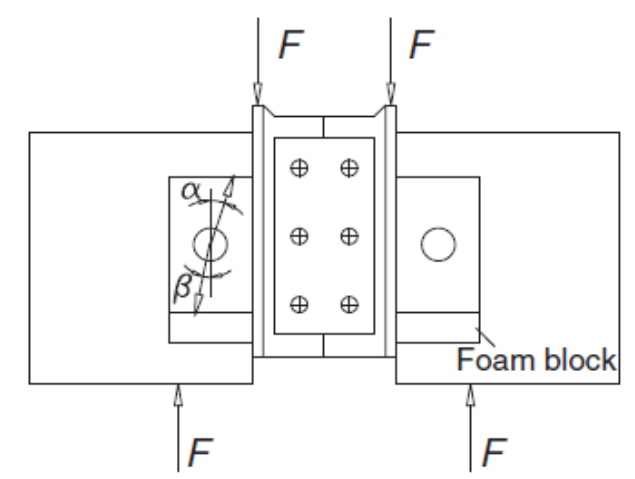

Figure 3. Conventional push-out test layout and deviation angle [9].

As an alternative to the push-out test, some researchers have proposed a new shear test setup, called plug-in test [9]-[12], in which the typical specimen consists of a single perforated steel plate embedded in a reinforced concrete block. A vertical compression load is applied directly to the top of the perforated steel plate, which slides inside the concrete block (Figure 4). This setup eliminates the deviation angle as the load is centered and vertically aligned with the connector and allows simulating situations where the connector is deeply embedded in the concrete.

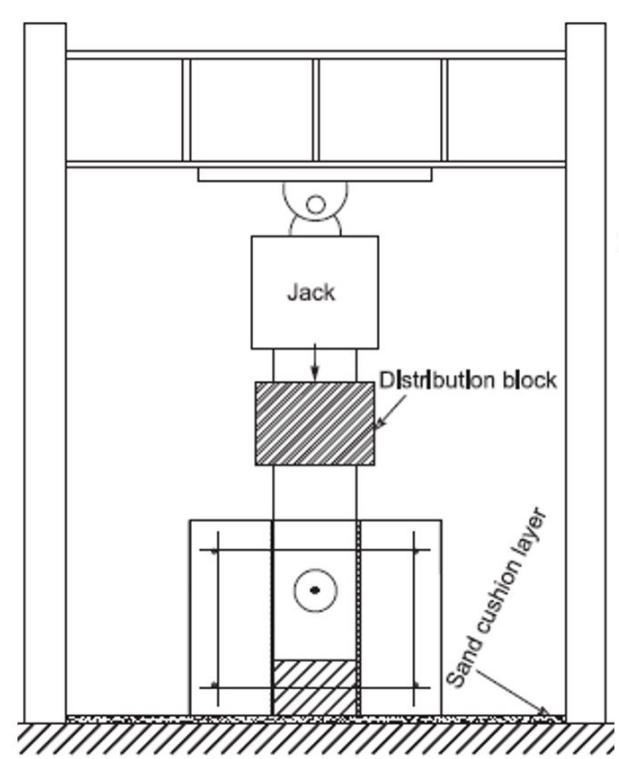

a)

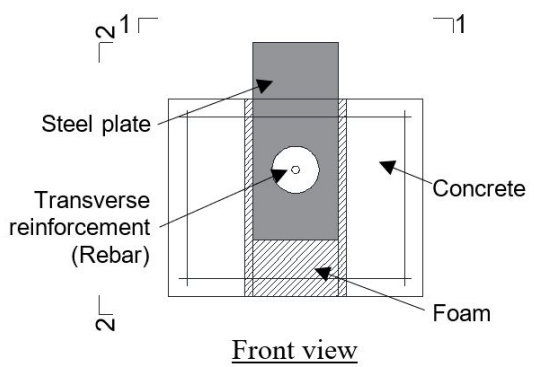

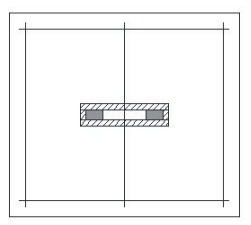

$1-1$

$\underline{\text { Top view }}$

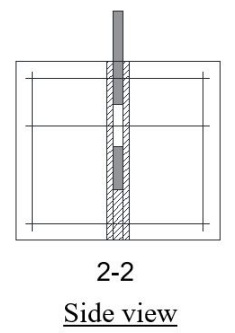

b)

Figure 4. Plug-in test a) setup and b) specimen details (adapted from [9]). 


\subsubsection{Shear tests with single-hole specimens}

The CFH shear strength is determined by the combination of the individual contributions of the transverse rebar in the hole, the concrete dowel formed by the concrete that fills the hole, the bond and friction between the steel plate and the concrete. The end bearing resistance of the CFH rib (Figure 2a) is not present in every application and will not be addressed in this paper. In order to study each of these contributing factors and, aiming at the application of CFH in different design applications, different authors performed shear tests with single CFH in push-out [12], [13] and plugin [9]-[12] configurations.

Su et al. [9] carried out 15 plug-in shear tests with single CFH specimens, in which the influence of the hole diameter and the presence of transverse reinforcement on the strength of the connector were evaluated. Reinforcement failure was observed in the tests, which rarely occurs in conventional push-out tests. From the test results, it was concluded that the plug-in shear test can eliminate the influence of friction and the deviation angle on the performance of the connector, and that the $\mathrm{CFH}$ has higher stiffness than stud-bolts.

He et al. [10] performed 12 plug-in tests divided into six specimen groups, each one of them varied in presenting steel-concrete bond, transverse rebar in the hole and concrete dowel (there were specimens without hole in the steel plate). From the test results, it was possible to determine the contribution of each strength component (concrete dowel, transverse rebar and bond) in the connector's overall strength, as shown in Figure 5.

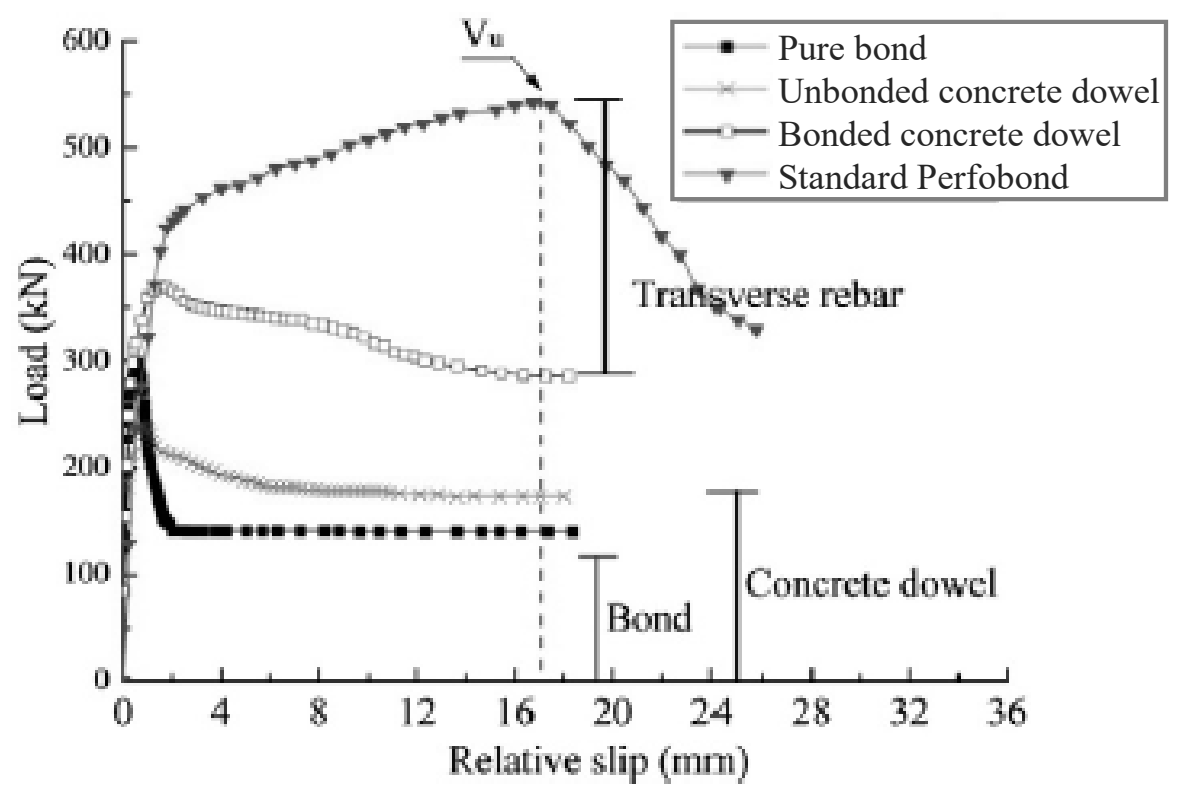

Figure 5. Analytical diagram of strength components of the CFH [10].

Zheng et al. [13] performed 9 push-out shear tests with single CFH specimens with transverse rebar in the hole, in which the influence of the hole diameter on the behavior of the CFH was evaluated. It was observed that both strength and stiffness of the connector increase as the hole diameter is enlarged, though the strength grows at a decreasing rate as the confinement effect of transverse rebar on concrete becomes weaker when the hole gets larger.

Nakajima and Nguyen [11], conducted 34 plug-in shear tests in order to evaluate the influence of the transverse reinforcement in the CFH strength. The specimens varied in transverse rebar diameter, hole diameter, plate thickness and material properties. It was observed that the transverse rebar in the hole contributes to the strength of the CFH by suppressing the opening of the shear fracture surface and by the dowel action. However, when the transverse rebar diameter is large relative to the hole diameter, it moves through the concrete within the hole which reduces the shear surface of the concrete dowel. To prevent this effect, the rebar bending stiffness must be adjusted to the compressive stiffness of its surrounding concrete.

Xiao et al. [12] performed 12 push-out and 12 plug-in tests to compare the mechanical behavior of CFH in conventional composite beams with that in a steel-concrete hybrid bridge transition, where the holes are deeply 
embedded in concrete. In these tests, the thickness of the steel plate and the compressive strength of the concrete were varied. It was observed that the failure mode is related to concrete spalling in the push-out tests and to the transverse rebar rupture in the plug-in tests, with plug-in tests show significantly higher strength than push-out tests. It was also observed that the test configuration has little influence on the initial stiffness, however, the degradation of the stiffness is associated with the concrete slab cracking in the push-out tests and the steel yielding of the transverse rebar in the plug-in tests.

From these 5 authors, 92 single-hole shear tests were extracted, totaling 30 variations of the connector. Their main characteristics are presented in Table 1.

\subsection{Predicting formulations for CFH shear strength}

Since the development of steel plate connectors with holes, different analytical models have been proposed to calculate the shear capacity of CFH (Table 2). Oguejiofor and Hosain [7], [14]; Hosaka et al. [15]; Medberry and Shahrooz [16]; Veríssimo [17]; Al Darzi et al. [18]; Ahn et al. [19] and Zheng et al. [13] derived regression analysis equations, evaluating the shear strength of CFH, obtained by means of push-out tests. He et al. [10] and Nakajima and Nguyen [11] proposed analytical models based on plug-in tests results, Zhao and Liu [20] based their formulation both push-out and plug-in test results and Braun [21] proposed a formulation for the case of application of the CFH in composite slim floor beam (CoSFB).

Table 1. Main geometric and material properties of the experimental specimens.

\begin{tabular}{|c|c|c|c|c|c|c|c|}
\hline Author & Specimen & $\begin{array}{c}\text { Test } \\
\text { setup }\end{array}$ & $\begin{array}{l}\text { Concrete } \\
\text { strength, } \\
f_{c} \text { (MPa) } \\
\end{array}$ & $\begin{array}{c}\text { Hole } \\
\text { diameter, } \\
d(\mathrm{~mm})\end{array}$ & $\begin{array}{c}\text { Plate } \\
\text { thickness, } t \\
\text { (mm) }\end{array}$ & $\begin{array}{l}\text { Diameter of } \\
\text { the transverse } \\
\text { rebar, } d_{s}(\mathrm{~mm})\end{array}$ & $\begin{array}{c}\text { Average } \\
\text { ultimate } \\
\text { load, } P_{u}(\mathrm{kN}) \\
\end{array}$ \\
\hline \multirow{5}{*}{ Su et al. [9] } & SCP-50 & Plug-in & 47.12 & 50 & 20 & 0 & 206.64 \\
\hline & SCP-60 & Plug-in & 47.12 & 60 & 20 & 0 & 314.09 \\
\hline & SCP-75 & Plug-in & 47.12 & 75 & 20 & 0 & 386.82 \\
\hline & SBP-24 & Plug-in & 47.12 & 24 & 20 & 22 & 316.75 \\
\hline & SBP-60 & Plug-in & 47.12 & 60 & 20 & 22 & 411.51 \\
\hline \multirow{5}{*}{ He et al. [10] } & C-b0r0d1 & Plug-in & 46.1 & 60 & 25 & 0 & 246.5 \\
\hline & C-b1r0d1 & Plug-in & 46.1 & 60 & 25 & 0 & 370 \\
\hline & C-b1r1d0 & Plug-in & 46.1 & 21 & 25 & 20 & 325.5 \\
\hline & C-b0r1d1 & Plug-in & 46.1 & 60 & 25 & 20 & 449 \\
\hline & C-b1r1d1 & Plug-in & 46.1 & 60 & 25 & 20 & 547 \\
\hline \multirow{3}{*}{ Zheng et al. [13] } & CP-1 & Push-out & 59.5 & 50 & 20 & 20 & 388.77 \\
\hline & $\mathrm{CP}-2$ & Push-out & 59.5 & 60 & 20 & 20 & 426.17 \\
\hline & $\mathrm{CP}-3$ & Push-out & 59.5 & 75 & 20 & 20 & 514.23 \\
\hline \multirow{11}{*}{ Nakajima and Nguyen [11] } & D30T12R10 & Plug-in & 32.15 & 30 & 12 & 10 & 90.27 \\
\hline & D40T12R13 & Plug-in & 29 & 40 & 12 & 13 & 177.96 \\
\hline & D40T12R16 & Plug-in & 29 & 40 & 12 & 16 & 238.64 \\
\hline & D60T12R10 & Plug-in & 32.27 & 60 & 12 & 10 & 250.18 \\
\hline & D60T12R13 & Plug-in & 32.5 & 60 & 12 & 13 & 238.21 \\
\hline & D60T12R16 & Plug-in & 33.3 & 60 & 12 & 16 & 246.57 \\
\hline & D60T19R16 & Plug-in & 34.1 & 60 & 19 & 16 & 242.28 \\
\hline & D60T25R16 & Plug-in & 34.1 & 60 & 25 & 16 & 269.53 \\
\hline & D70T12R13 & Plug-in & 29 & 70 & 12 & 13 & 279.59 \\
\hline & D70T12R16 & Plug-in & 29 & 70 & 12 & 16 & 301.24 \\
\hline & D90T12R10 & Plug-in & 32.15 & 90 & 12 & 10 & 413.72 \\
\hline \multirow{6}{*}{ Xiao et al. [12] } & ST16 & Push-out & 41.68 & 60 & 20 & 16 & 222.9 \\
\hline & ST16C & Push-out & 26.56 & 60 & 20 & 16 & 159.6 \\
\hline & ST16T & Push-out & 41.68 & 60 & 8 & 16 & 158.35 \\
\hline & PT16 & Plug-in & 41.68 & 60 & 20 & 16 & 396.93 \\
\hline & PT16C & Plug-in & 26.56 & 60 & 20 & 16 & 328.08 \\
\hline & PT16T & Plug-in & 41.68 & 60 & 8 & 16 & 246 \\
\hline
\end{tabular}


Table 2. Some formulations for predicting the strength of CFH.

\begin{tabular}{|c|c|}
\hline \multicolumn{2}{|r|}{ Predicting models } \\
\hline Oguejiofor and Hosain [7] & $q=0.590 A_{c c} \sqrt{f_{c}}+1.233 A_{t r} f_{y}+2.871 n d^{2} \sqrt{f_{c}}$ \\
\hline Oguejiofor and Hosain [14] & $q=4.50 h t f_{c}+3.31 n d^{2} \sqrt{f_{c}}+0.91 A_{t r} f_{y}$ \\
\hline \multirow{2}{*}{ Hosaka et al. [15] } & $Q=3.38 d^{2} \sqrt{t / d} f_{c}-39$, without transverse rebars* \\
\hline & $Q=1.45\left[\left(d^{2}-d_{s}^{2}\right) f_{c}+d_{s}^{2} f_{u}\right]-26.1$, with transverse rebars* \\
\hline Medberry and Shahrooz [16] & $P=0.747 b h_{e c s} \sqrt{f_{c}}+0.413 b_{f} L_{c}+1.304 n d^{2} \sqrt{f_{c}}+0.9 A_{t r} f_{y}$ \\
\hline Veríssimo [17] & $q=3.68 \sqrt{h / b} h t f_{c}+2.60 n d^{2} \sqrt{f_{c}}+0.13 A_{c c} \sqrt{f_{c}}+34.3 \times 10^{6}\left(A_{t r} / A_{c c}\right)$ \\
\hline Al-Darzi et al. [18] & $q=255309+0.762 h t f_{c}-7.59 \times 10^{-4} A_{t r} f_{y}+3.97 n d^{2} \sqrt{f_{c}}$ \\
\hline Ahn et al. [19] & $\begin{array}{l}q=3.14 h t f_{c}+2.98 n d^{2} \sqrt{f_{c}}+1.21 A_{t r p} f_{y}, \text { for single CFH rib } \\
q=2.76 h t f_{c}+2.61 n d^{2} \sqrt{f_{c}}+1.06 A_{t r p} f_{y}, \text { for twin CFH rib }\end{array}$ \\
\hline Zhao and Liu [20] & $Q=1.38\left(d^{2}-d_{s}^{2}\right) f_{c}+1.24 d_{s}^{2} f_{y}$ \\
\hline He et al. [10] & $q=\tau_{b} A_{b}+1.06 A_{c} f_{c u}+2.09 A_{s} f_{y} ; \tau_{b}=-0.022 f_{c u}+0.306 \sqrt{f_{c u}}-0.573$ \\
\hline Zheng et al. [13] & $Q=1.76 \alpha_{A}\left(A-A_{s}\right) f_{c}+1.58 A_{s} f_{y} \alpha_{A}=3.80\left(A_{s} / A\right)^{2 / 3}$ \\
\hline \multirow[b]{2}{*}{ Nakajima and Nguyen [11] } & $q=0.15 A f_{c}^{0.65} A_{l}^{0.43} t^{-0.5}$, without transverse rebars* \\
\hline & $\begin{array}{l}q=0.15 \alpha\left(A-A_{s}\right) f_{c}^{0.65} A_{l}^{0.43} t^{-0.5}+0.84 d_{s} f_{y} d^{0.1} t^{0.8} ; \alpha=6.9 d_{s}^{0.4} d^{-0.7} \text {, with } \\
\text { transverse rebars* }\end{array}$ \\
\hline Braun $[21]$ & $q=36.919\left(f_{c} t d \times 10^{-3}\right)^{0.287}+\left(\pi d_{s}^{2} f_{y} / 2 \sqrt{3}\right) \times 10^{-3}$ \\
\hline \multicolumn{2}{|c|}{ Notation: } \\
\hline \multicolumn{2}{|c|}{$\begin{array}{l}A \text { is the hole area }\left(\mathrm{mm}^{2}\right) ; \\
A_{b} \text { is the area of the contact surface between the steel plate and the concrete } \\
\left(\mathrm{mm}^{2}\right) ; \\
A_{c} \text { is the section area of the concrete dowel, } A_{c}=\pi\left(d^{2}-d_{s}^{2}\right) / 4 ; \\
A_{c c} \text { is the shear area of concrete per connector }\left(\mathrm{mm}^{2}\right) \text {, which is the longitudinal } \\
\text { slab area minus the connector area; } \\
A_{l} \text { is the side area of the concrete block }\left(\mathrm{mm}^{2}\right) ; \\
A_{s} \text { is the section area of the transverse rebar in one hole }\left(\mathrm{mm}^{2}\right) ; \\
A_{t r} \text { is the total area of transverse reinforcement }\left(\mathrm{mm}^{2}\right) ; \\
A_{t r p} \text { is the area of the transverse rebars in the rib holes }\left(\mathrm{mm}^{2}\right) ; \\
L_{c} \text { is the contact length between the steel and the concrete per flange }(\mathrm{mm}) ; \\
P \text { is the shear capacity per slab using CFH (N); } \\
Q \text { is the shear capacity per hole of CFH (N); } \\
b \text { is the concrete slab thickness (mm); }\end{array}$} \\
\hline
\end{tabular}

The range of values of the geometric and material parameters for which the formulations were derived can be observed in Table 3.

Table 3. Range of values and test setup from which the formulations were derived.

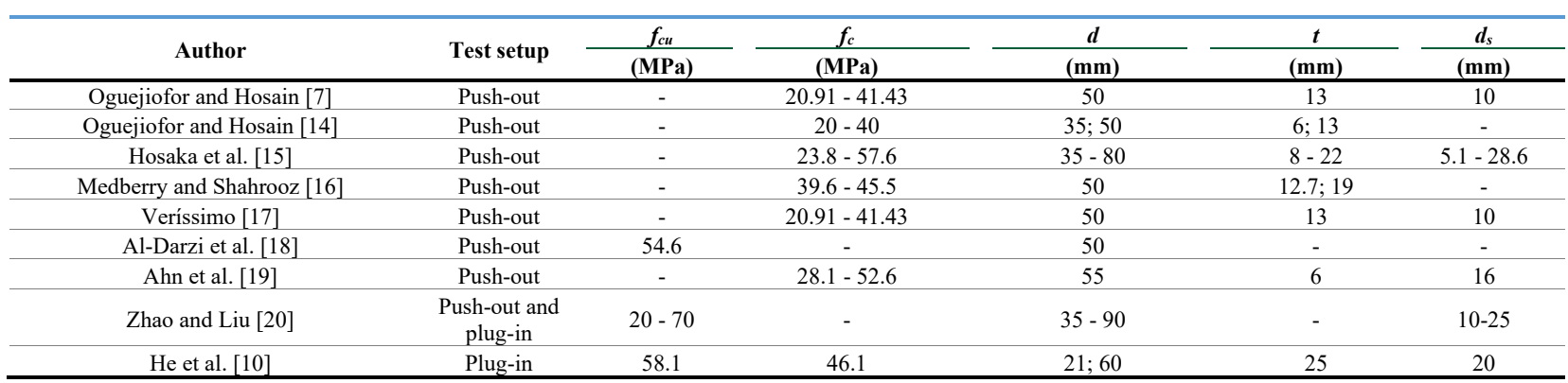


Table 3. Continued...

\begin{tabular}{|c|c|c|c|c|c|c|}
\hline Author & Test setup & $\begin{array}{c}f_{c u} \\
(\mathrm{MPa}) \\
\end{array}$ & $\begin{array}{c}f_{c} \\
\text { (MPa) } \\
\end{array}$ & $\begin{array}{c}d \\
(\mathrm{~mm})\end{array}$ & $\begin{array}{c}t \\
(\mathrm{~mm})\end{array}$ & $\begin{array}{c}d_{s} \\
(\mathrm{~mm}) \\
\end{array}$ \\
\hline Zheng et al. [13] & Push-out & 70.3 & 59.5 & $50 ; 60 ; 75$ & 20 & 20 \\
\hline Nakajima and Nguyen [11] & Plug-in & - & $29-34.1$ & $30 ; 40 ; 60 ; 70 ; 90$ & $12 ; 19 ; 25$ & $10 ; 13 ; 16$ \\
\hline Braun $[21]$ & Slim Floor & $30-67$ & $25-55$ & $25 ; 40$ & $7.5 ; 15.5$ & 12 \\
\hline \multicolumn{7}{|c|}{$\begin{array}{l}\text { Notation: } \\
\text { hole diameter }(\mathrm{mm}) \text {; } \\
\text { erse rebar that passes through the hole }(\mathrm{mm}) \text {; } \\
\text { concrete strength - cylinder }(\mathrm{MPa}) \text {; } \\
\text { e concrete strength - cube }(\mathrm{MPa}) \\
\text { nnector thickness }(\mathrm{mm}) \text {. }\end{array}$} \\
\hline
\end{tabular}

\subsection{Statistical evaluation}

Annex D from EN 1990:2002 [6] presents a standard procedure to derive design equations based on statistical evaluations. Part of this method, used in this work, involves a number of discrete steps which must be followed until good compatibility between the equation and experimental data is achieved:

- Step 1: develop a design model for the theoretical resistance that cover the basic variables that affect the resistance at relevant limit state;

- Step 2: substitute the measured properties into the resistance function so as to obtain theoretical values $r_{t i}$ to form the basis of a comparison with the experimental values $r_{e i}$ from the tests, and plot the points representing pairs of corresponding values $\left(r_{t i}, r_{e i}\right)$, as indicated in Figure 6;

- Step 3: Estimate the mean value correction factor $b$ (Equation 1)

$b=\frac{\sum r_{e} r_{t}}{\sum r_{t}^{2}}$

where $r_{e}$ is the experimental resistance value and $r_{t}$ is the theoretical resistance determined from the resistance function.

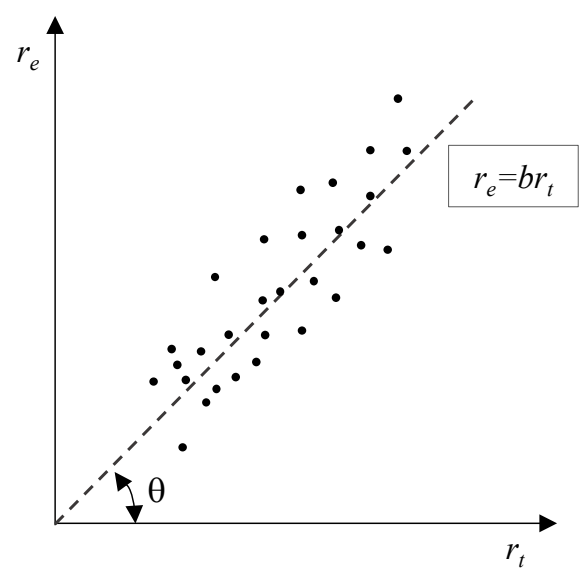

Figure 6. $r_{t}($ theoretical resistance $) \times r_{e}($ experimental resistance $)$ diagram [6]

- Step 4: Estimate the coefficient of variation of the errors $V_{\delta}$ (Equation 6), based on log-normal distribution

$r_{e i}=b r_{t i} \delta_{i} \rightarrow \delta_{i}=\frac{r_{e i}}{b r_{t i}}$ 
$\Delta_{i}=\ln \left(\delta_{i}\right)$

$\bar{\Delta}=\frac{1}{n} \sum_{i=1}^{n} \Delta_{i}$

$s_{\Delta}^{2}=\frac{1}{n-1} \sum_{i=1}^{n}\left(\Delta_{i}-\bar{\Delta}\right)^{2}$

$V_{\delta}=\sqrt{\exp \left(s_{\Delta}^{2}\right)-1}$

where $r_{e i}$ is the experimental resistance for specimen $i, r_{t i}$ is the theoretical resistance determined from the resistance function, $\delta_{i}$ is the error term, $\Delta_{i}$ is the logarithm of the error term, $\bar{\Delta}$ is the mean value of the logarithm of the error term, $n$ is the number of experimental results and $s_{\Delta}^{2}$ is the estimate value of variance of the term $\Delta$.

- Step 5: Analyze compatibility of the test population with the resistance function analyzed, based on the scatter of the $\left(r_{e i}, r_{t i}\right)$ values.

If the scatter values are too high to give an economical design, the design model can be modified taking into account parameters which has previously been ignored or modifying the parameters $b$ and $V_{\delta}$ by the analysis of population subsets.

\section{METHODOLOGY}

The test results presented in 2.1.2, excluding the specimens with no hole by He et al. [10], were gathered and their geometric and material parameters were extracted from the specimens' descriptions (Table 1). These parameters were then applied to the 12 formulations presented in 2.2 (Table 2).

The concrete compressive strength obtained with cubic specimens was assumed to be 1.25 times that obtained with cylindrical specimens [22]. The bond between steel and concrete was only considered when authors did not use means to eliminate it, such as grease, oil and foam. For those formulations that consider an end bearing resistance, the equation term related to this contribution was discarded as none of the specimens in this work have this feature. For formulations with parameters referring specifically to slab geometry $\left(A_{c c}, b\right.$, $\left.h_{e c s}\right)$, the concrete block of plug-in specimens was converted into slab by taking the block dimension that runs parallel to the steel plate width as corresponding to the slab thickness.

With the results obtained, the standard evaluation procedure in 2.3 was applied and, based on the correction factor $(b)$ and coefficient of variation $\left(V_{\delta}\right)$ values, the formulations were evaluated. The final aim of this analysis was to determine the formulations that can best predict the CFH shear strength for the different studied shear test setups and application possibilities.

\section{RESULTS AND DISCUSSIONS}

Figure 7 shows the ordered pairs of strength values obtained from the formulations $\left(r_{t}\right)$ and from the shear tests $\left(r_{e}\right)$, where plug-in test results are denoted by circles and push-out test results by triangles. Then, the statistical analysis was performed, resulting in correction factors $(b)$ and coefficients of variation $\left(V_{\delta}\right)$ for each formulation, which are presented in Table 4 and Figure 8. Based on the statistical analysis and experimental observations of the CFH behavior, critical analysis and discussion of the constituting terms of the formulations were also carried out.

Additionally, it was done an evaluation of the sensitivity of the formulations' terms to variations in the concrete's compressive strength $\left(f_{c}\right)$, hole diameter $(d)$, thickness of the connector plate $(t)$ and diameter of the transverse rebar $\left(d_{s}\right)$ when the other parameters are kept constant, as shown in Figure 9. For this, only the sets of shear tests in which the author kept constant all the parameters that could influence the result while varying one parameter of interest were selected. The results of these test sets are presented by points in graphs that relate the parameter of interest $\left(f_{c}, d, t\right.$ and $\left.d_{s}\right)$ to the obtained strength value $(q)$. Overlaying these experimental points and the curves $q \times f_{c}, d, t$ and $d_{s}$ provided by the formulations when inputted the same parameters kept constant in the shear tests, it is possible to evaluate if the formulations adequately capture the trends observed experimentally. 


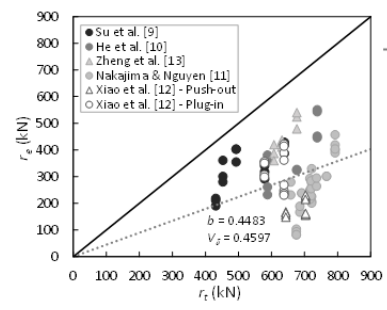

a) Oguejiofor \& Hosain [7]

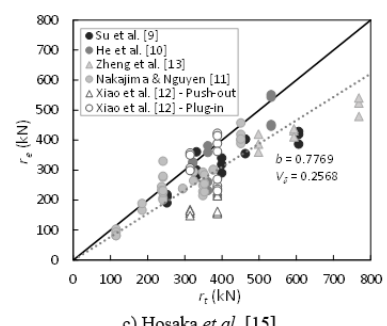

c) Hosaka et al. [15]

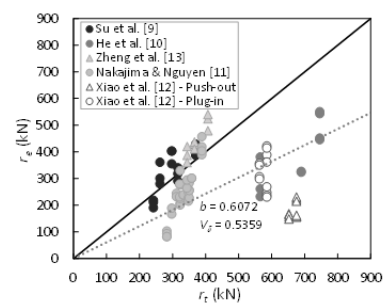

e) Veríssimo [17]

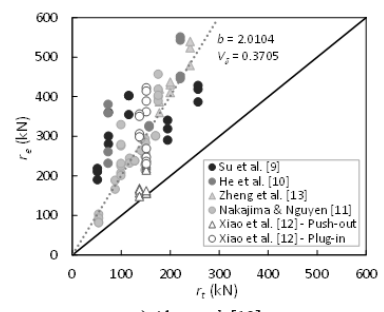

g) Ahn et al. [19]

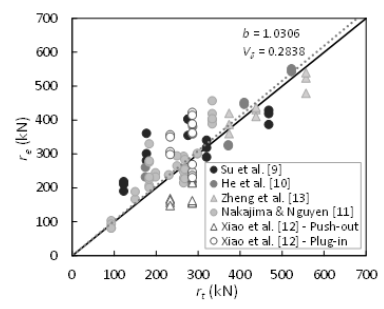

i) He et al. [10]

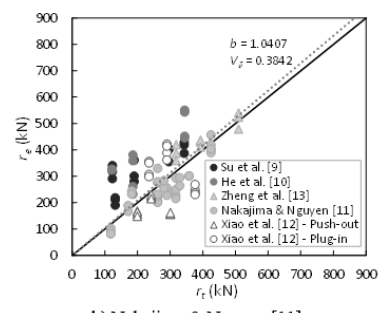

k) Nakajima \& Nguyen [11]

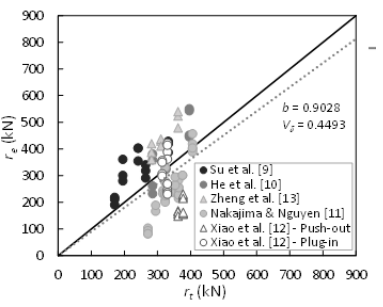

b) Oguejiofor \& Hosain [14]

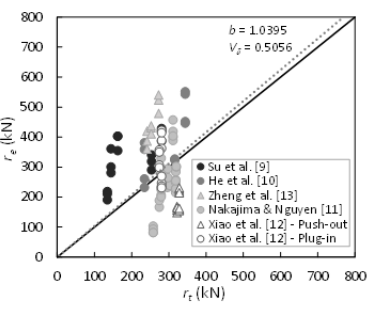

d) Medberry \& Shahrooz [16]

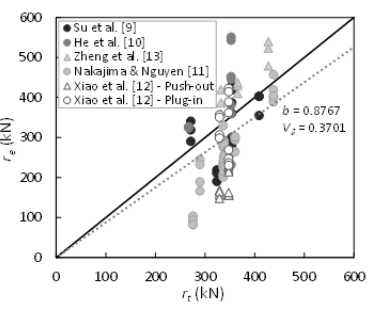

f) Al-Darzi et al. [18]

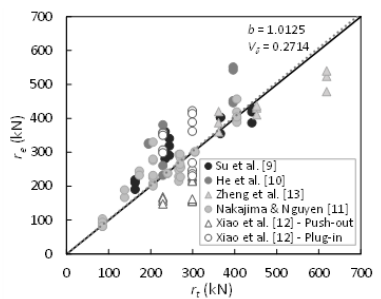

h) Zhao \& Liu [20]

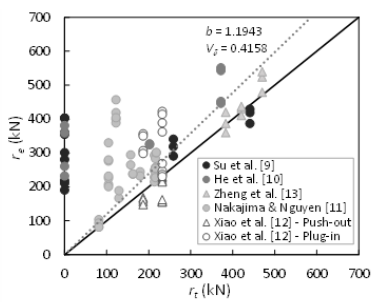

j) Zheng et al. [13]

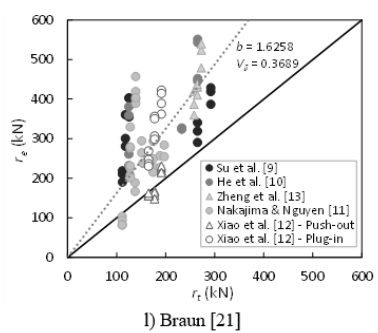

Figure 7. Relation between experimental strength values $\left(r_{e}\right)$ and theoretical strength values determined from analyzed formulations $\left(r_{t}\right)$. 
Given the small number of experimental points available for this analysis (Figure 9), the trend evaluation of the curves was done simply by comparing the average slope of each curve with the slope of a line connecting the first to the last experimental point, within the experimental values interval. The average slopes of the curves are given in Table 5 as a factor of the slope defined by the experimental points.

Table 4. Statistical analysis of the formulations: equations ranked by coefficient of variation $\left(V_{\delta}\right)$.

\begin{tabular}{ccc}
\hline Formulation & $\boldsymbol{V} \boldsymbol{\delta}$ & $\boldsymbol{b}$ \\
\hline Hosaka et al. [15] & 0.2568 & 0.7769 \\
\hline Zhao and Liu [20] & 0.2714 & 1.0125 \\
\hline He et al. [10] & 0.2838 & 1.0306 \\
\hline Braun [21] & 0.3689 & 1.6258 \\
\hline Al-Darzi et al. [18] & 0.3701 & 0.8767 \\
\hline Ahn et al. [19] & 0.3705 & 2.0104 \\
\hline Nakajima and Nguyen [11] & 0.3842 & 1.0407 \\
\hline Zheng et al. [13] & 0.4158 & 1.1943 \\
\hline Oguejiofor and Hosain [14] & 0.4493 & 0.9028 \\
\hline Oguejiofor and Hosain [7] & 0.4597 & 0.4483 \\
\hline Medberry and Shahrooz [16] & 0.5056 & 1.0395 \\
\hline Veríssimo [17] & 0.5359 & 0.6072 \\
\hline
\end{tabular}

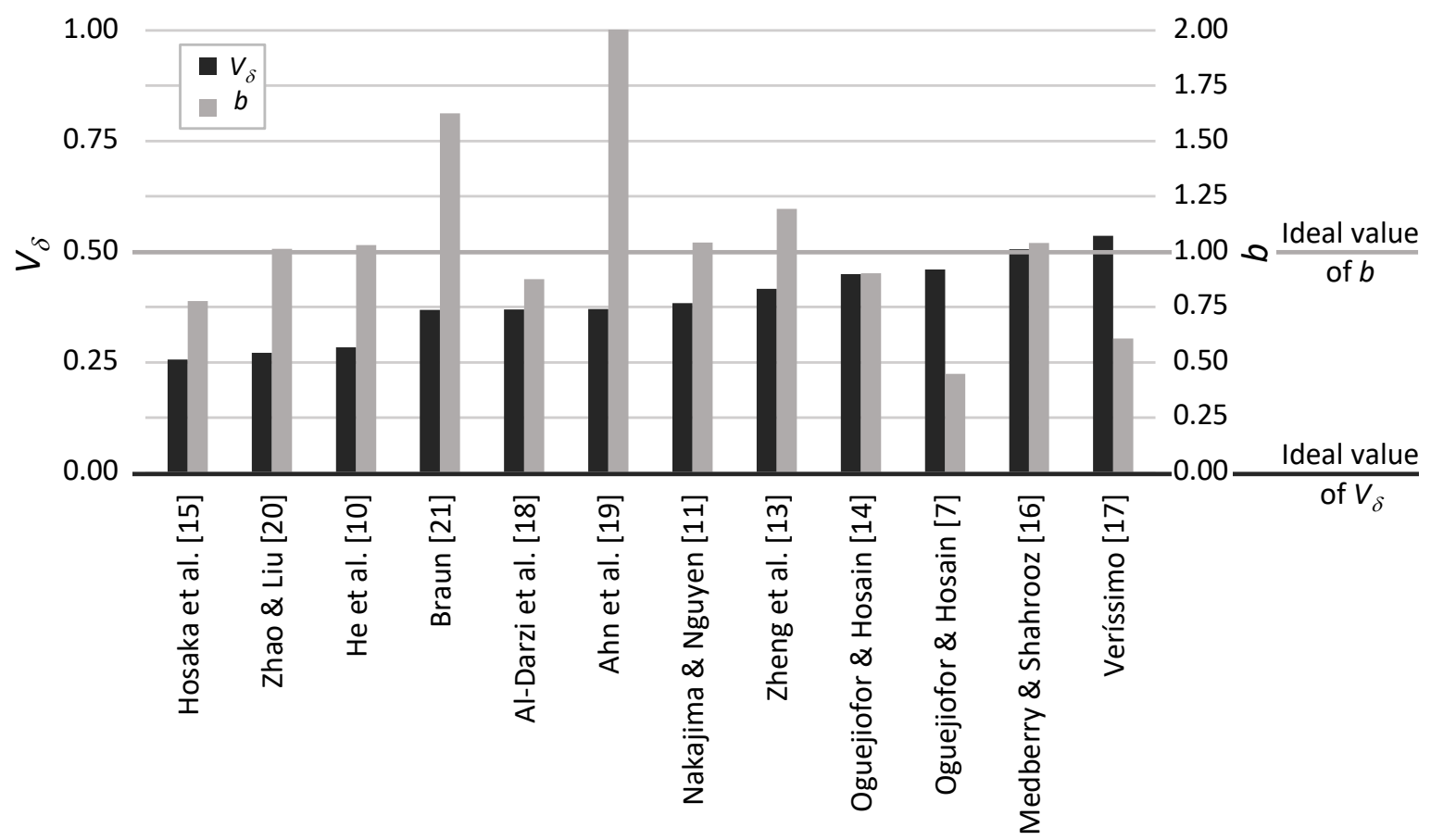

Figure 8. Statistical analysis result: formulations in order of coefficient of variation $\left(V_{\delta}\right)$. 

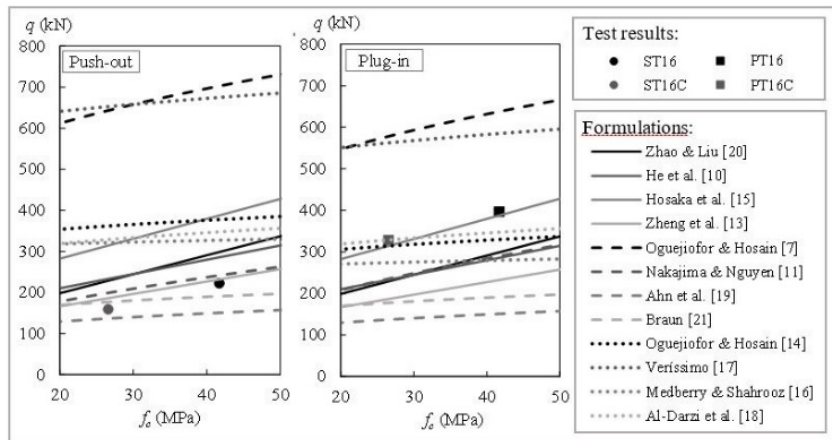

a) variation of compressive concrete strength $\left(f_{c}\right)$

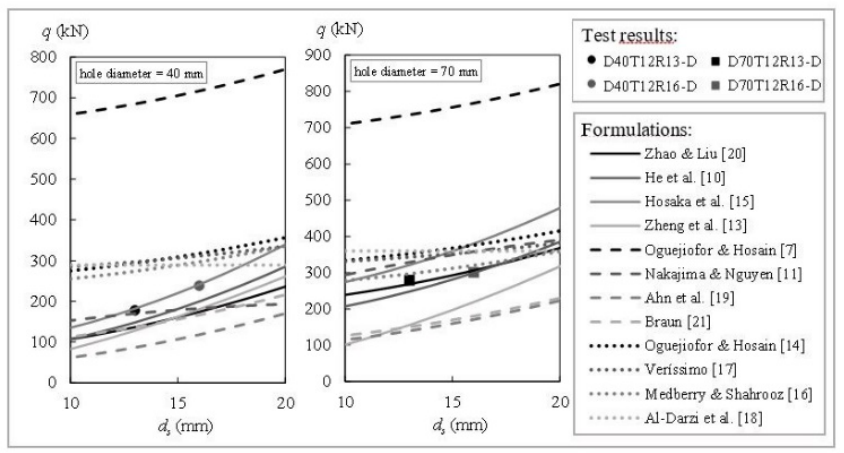

b) variation of diameter of the transverse rebar $\left(d_{s}\right)$
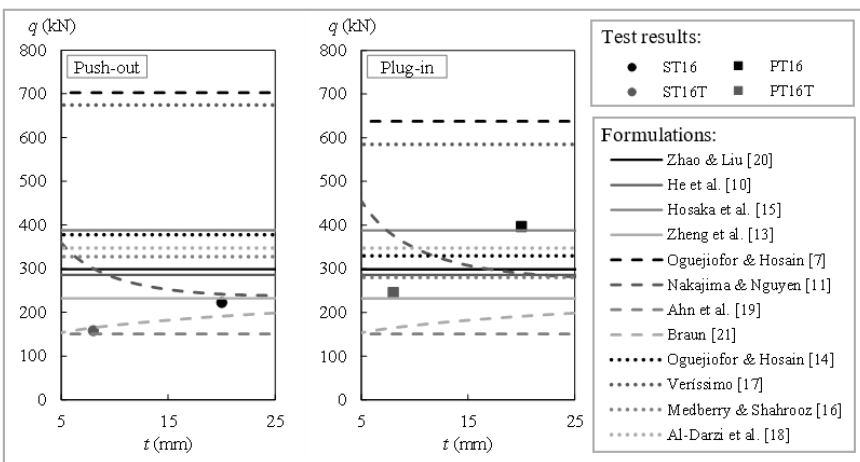

c) variation of Perfobond connector thickness $(t)$

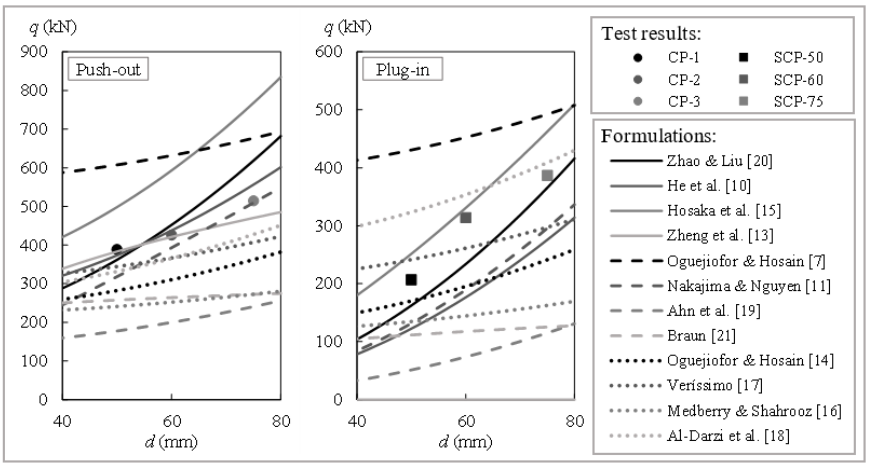

d) variation of hole diameter $(d)$

Figure 9. Strength values $(q)$ obtained in shear tests and predicted by formulations observing the variation of a) compressive concrete strength, b) diameter of the transverse rebar that passes through the hole, c) CFH rib thickness and d) hole diameter. 
Table 5. Formulations ranked by approximation of average slope of $q \times f_{c}, d, t$ and $d_{s}$ curves in relation to the slope defined by experimental points.

\begin{tabular}{|c|c|c|c|c|c|c|c|c|c|}
\hline \multirow[t]{2}{*}{ Formulation } & \multicolumn{2}{|c|}{$\begin{array}{c}\text { Variation of } \\
\text { compressive concrete } \\
\text { strength } \\
\end{array}$} & \multicolumn{2}{|c|}{$\begin{array}{c}\text { Variation of diameter } \\
\text { of the transverse } \\
\text { rebar }\end{array}$} & \multicolumn{2}{|c|}{$\begin{array}{c}\text { Variation of plate } \\
\text { thickness }\end{array}$} & \multicolumn{2}{|c|}{$\begin{array}{l}\text { Variation of hole } \\
\text { diameter }\end{array}$} & \multirow[t]{2}{*}{ Average } \\
\hline & push-out & plug-in & $d=40$ & $\mathrm{~d}=\mathbf{7 0}$ & push-out & plug-in & push-out & plug-in & \\
\hline Zhao and Liu [20] & 1.10 & 1.01 & 0.62 & 1.73 & 0.00 & 0.00 & 2.05 & 1.13 & 0.95 \\
\hline He et al. [10] & 0.83 & 0.76 & 0.85 & 2.38 & 0.00 & 0.00 & 1.46 & 0.85 & 0.89 \\
\hline Hosaka et al. [15] & 1.16 & 1.06 & 0.98 & 2.74 & 0.00 & 0.00 & 2.15 & 1.17 & 1.16 \\
\hline Zheng et al. [13] & 0.72 & 0.66 & 0.87 & 2.93 & 0.00 & 0.00 & 0.69 & - & 0.84 \\
\hline Oguejiofor and Hosain [7] & 0.94 & 0.87 & 0.53 & 1.48 & 0.00 & 0.00 & 0.55 & 0.34 & 0.59 \\
\hline Nakajima and Nguyen [11] & 0.67 & 0.79 & 0.21 & 1.36 & -0.91 & -0.57 & 1.52 & 0.91 & 0.50 \\
\hline Ahn et al. [19] & 0.22 & 0.20 & 0.52 & 1.45 & 0.00 & 0.00 & 0.50 & 0.35 & 0.41 \\
\hline Braun $[21]$ & 0.22 & 0.20 & 0.49 & 1.38 & 0.41 & 0.17 & 0.12 & 0.08 & 0.38 \\
\hline Oguejiofor and Hosain [14] & 0.25 & 0.23 & 0.39 & 1.09 & 0.00 & 0.00 & 0.64 & 0.39 & 0.37 \\
\hline Veríssimo [17] & 0.35 & 0.32 & 0.24 & 0.67 & 0.00 & 0.00 & 0.50 & 0.31 & 0.30 \\
\hline Medberry and Shahrooz [16] & 0.10 & 0.09 & 0.38 & 1.08 & 0.00 & 0.00 & 0.25 & 0.16 & 0.26 \\
\hline Al-Darzi et al. [18] & 0.29 & 0.27 & 0.00 & 0.00 & 0.00 & 0.00 & 0.76 & 0.47 & 0.23 \\
\hline
\end{tabular}

\subsection{Statistical analysis of the formulations}

From the results of the statistical analysis, it can be observed that the formulations that shown lower values of coefficient of variation $\left(V_{\delta}\right)$, therefore, lower scatter of data, were those by Hosaka et al. [15], Zhao and Liu [20] and He et al. [10], in that order.

Although the formulation by Hosaka et al. [15] presented the lowest coefficient of variation, its correction factor $(b)$ was $22.31 \%$ lower than one, evidencing the need to adjust the parameters of the formulation.

The formulations by Zhao and Liu [20] and He et al. [10] also shown low coefficients of variation when compared to the other formulations and a correction factors very close to one, i.e., $\theta \approx 45^{\circ}$ (Figure 6), which characterizes them as the best formulations. The better compatibility of such formulations with the experimental data is due to the fact that He et al. [10] performed a comparative analysis that effectively isolated the influence of each strength component (concrete dowel, transverse rebar in the hole and bond) from single-hole plug-in tests (Figure 5) and that Zhao and Liu [20] derived their formulation from 168 test results, both plug-in and push-out.

The other formulations presented higher scatter of the data even though in some cases [11], [16] the correction factor was close to one, as desired.

\subsection{Analysis of the terms that constitute the formulations}

Although some formulations may at times provide predictions close to the experimental results, the terms that constitute their equations may not consistently represent the mechanical behavior of the connection [10], [13]; therefore, it was conducted in this work an analysis of the terms that constitute these formulations.

It is noted that the constituting terms of some formulations are specifically related to the test configuration from which they were derived [7], [13], [16]; making it difficult to apply them in certain design applications. Regarding the formulations by Oguejiofor and Hosain [7] and Medberry and Shahrooz [16], because they were derived from push-out tests, these authors specified a term to address the splitting of the concrete slab observed in the tests, however, this failure mode does not occur in plug-in tests and, in composite beam applications, it is usually resisted by the slab's transverse reinforcement (see item 6.6.6 of EN 1994.1.1:2004 [8]), not by the connector itself. Regarding the formulation by Zheng et al. [13], it is valid only when there is transverse rebar passing through the hole, in the absence of this, such formulation provides null values, which had to be discarded in the statistical analysis.

Observing the points referring to the experimental results of Xiao et al. [12] in Figure 7, it is noted that for most formulations the results of the push-out (triangles) and plug-in (circles) tests laid vertically aligned in the diagrams, indicating that these formulations are unable to predict a strength increase as the depth of the connection increases. Only the formulation by Nakajima and Nguyen [11] was able to predict higher strength values for plug-in shear tests. The Oguejiofor and Hosain [7], [14]; Medberry and Sharooz [16] and Veríssimo [17] formulations showed the opposite trend, i.e., they incorrectly predicted higher strength for push-out tests.

In Figure 9c, it is noted a trend of strength increase as the thickness of the steel plate is increased, which was addressed only by Braun [21]. In the formulation by Nakajima and Nguyen [11] the plate thickness parameter $(t)$ has an exponential power of -0.5 in the first term of the equations which caused the hole's strength to decrease with an increase of plate thickness. The other formulations show no relation between the hole's strength and the plate thickness. 
By combining the analysis of the terms of the formulations with the statistical analysis, it is observed that, despite showing low scatter the formulation by Hosaka et al. [15] has constant terms to which no physical meaning has been attributed. The same happens with the formulation by Al-Darzi et al. [18], where in some cases the constant terms even exceed the expected strength value. Also, in this formulation [18] the transverse rebar in the hole contributes negatively to the connector strength, which was not observed in any other formulation and doesn't agree with the experimental observations in 2.1.2.

As for the two best ranked formulations in the statistical analysis (Zhao and Liu [20] and He et al. [10]), it is observed that they are basically constituted of a term regarding the contribution of the concrete dowels and another regarding the transverse rebar in the hole, thus defining the strength of the $\mathrm{CFH}$ as the sum of these two main strength components.

The sensitivity evaluation of the formulations' terms (Figure 9 and Table 5) showed that the three best ranked formulations in the statistical evaluation (Zhao and Liu [20], He et al. [10] and Hosaka et al. [15]) were also the ones that best captured the trends observed experimentally, as they resulted in curves with average slopes closer to those defined by the experimental points. This indicates that these equations showed better correlation with experimental data in 4.1 because they better describe the mechanical behavior of the connection and the influence of each isolated parameter.

However, it should be noted that none of the formulations adequately captured the influence that the plate thickness and depth of the connection have on hole strength. Therefore, it is suggested that, in addition to the geometric parameters already addressed by Zhao and Liu [20] and He et al. [10], plate thickness and depth of the connection should also be considered for predicting CFH shear strength. Also, a series of new push tests should be conducted in order to obtain more detailed curves relating of each of these parameters with the connector's strength. By doing so, according to Annex D of EN 1990: 2002 [6] (item D8.2.2.5 Step 5), a formulation with lower coefficient of variation could be obtained which would allow a more economical design.

\section{CONCLUSIONS}

In this work 12 formulations were evaluated for predicting the strength of CFH in 92 shear tests with single-hole specimens. It was considered that a formulation that adequately predicts the strength of a single hole, i.e., the fundamental aspect of $\mathrm{CFH}$ connections, is more suitable to be adapted and extrapolated to the various structural applications of this type of connection. From statistical and critical analysis, it was concluded that:

- the formulation proposed by Hosaka et al. [15] presented the lowest scatter of data, but its correction factor was the fifth furthest from one. Also, it has constant terms to which no physical meaning has been attributed, this makes it difficult to adapt this equation to different design conditions, since these terms cannot be related to the physical and geometric settings of a given situation;

- the formulations that presented lower scatter and correction factor value closer to one were the ones by Zhao and Liu [20] and He et al. [10], thus being considered the best formulations for obtaining the strength of CFH, both in plug-in and push-out tests. These formulations are basically constituted of a term referring to the contribution of concrete dowels and another referring to the contribution of the transverse rebars that passes through the hole;

- other formulations presented higher scatter, evidencing the need to review the parameters considered for deriving these formulations;

- among the formulations studied in this paper, it is suggested that the best three for predicting the strength of CFH are those by Zhao and Liu [20], He et al. [10] and Hosaka et al. [15], in that order;

- none of the formulations adequately expressed the influence that plate thickness and depth of the connection have on the hole strength. Moreover, there were few single-hole test results from which to draw curves relating the strength of the connector to its geometric and material parameters. Therefore, it is suggested to conduct further shear tests on the CFH so that the plate thickness and depth of the connector are included in the set of parameters that constitutes the formulations. Thus, more detailed curves relating of each individual parameter with the $\mathrm{CFH}$ strength can be drawn.

\section{ACKNOWLEDGEMENTS}

The authors wish to acknowledge the Coordenação de Aperfeiçoamento de Pessoal de Nível Superior (CAPES), Conselho Nacional de Desenvolvimento Científico e Tecnológico (CNPq), Fundação de Amparo à Pesquisa do Estado de Minas Gerais (FAPEMIG) and Universidade Federal de Minas Gerais (UFMG) for their support for the realization and dissemination of this study. 


\section{REFERENCES}

[1] F. Leonhardt, W. Andrä, H. P. Andrä, and W. Harre, "Neues, vorteilhaftes verbundmittel für stahlverbund-tragwerke mit hoher daurfestigkeit," Beton Stahlbetonbau, vol. 82, no. 12, pp. 325-331, Dec 1987, http://dx.doi.org/10.1002/best.198700500.

[2] ArcelorMittal Europe. "Slim floor: an innovative concept for floors, design guide." http://constructalia.arcelormittal.com (accessed Apr. 24, 2017).

[3] F. Xu, Z. Zhang, D. Wang, and W. Hulil, "Application of a perfobond rib shear connector group in a beam-arch hybrid bridge," Struct. Eng. Int., vol. 25, no. 4, pp. 414-418, 2015, http://dx.doi.org/10.2749/101686615X14355644770974.

[4] J. Vianna, L. F. Costa-Neves, P. C. G. S. Vellasco, and S. A. L. Andrade, "Structural behaviour of T-Perfobond shear connectors in composite girders: An experimental approach," Eng. Struct., vol. 30, no. 9, pp. 2381-2391, Sep 2008, http://dx.doi.org/10.1016/j.engstruct.2008.01.015.

[5] L. Peng-Zhen, C. Lin-feng, L. Yang, L. Zheng-lun, and S. Hua, "Study on mechanical behavior of negative bending region based design of composite bridge deck," Int. J. Civ. Eng., vol. 16, pp. 489-497, 2018, http://dx.doi.org/10.1007/s40999-017-0156-0.

[6] European Committee for Standardization, Basis of Structural Design, EN 1990:2002, 2002.

[7] E. C. Oguejiofor and M. U. Hosain, "A parametric study of perfobond rib shear connectors," Can. J. Civ. Eng., vol. 21, no. 4, pp. 614-625, 1994, http://dx.doi.org/10.1139/194-063.

[8] European Committee for Standardization, Design of Composite Steel and Concrete Structures - Part 1-1: General Rules and Rules for Buildings, EN 1994-1-1:2004, 2004.

[9] Q. T. Su, W. Wang, H. W. Luan, and G. T. Yang, "Experimental research on bearing mechanism of perfobond rib shear connectors," J. Construct. Steel Res., vol. 95, pp. 22-31, Apr 2014, http://dx.doi.org/10.1016/j.jcsr.2013.11.020.

[10] S. He, Z. Fang, Y. Fang, M. Liu, L. Liu, and A. S. Mosallam, "Experimental study on perfobond strip connector in steel-concrete joints of hybrid bridges," J. Construct. Steel Res., vol. 118, pp. 169-179, Mar 2016, http://dx.doi.org/10.1016/j.jcsr.2015.11.009.

[11] A. Nakajima and M. H. Nguyen, "Strain behavior of penetrating rebar in perfobond strip and its evaluation of shear resistance," $J$. JSCE, vol. 4, no. 1, pp. 1-18, 2016, http://dx.doi.org/10.2208/journalofjsce.4.1_1.

[12] L. Xiao, X. Li, and Z. J. Ma, "Behavior of perforated shear connectors in steel-concrete composite joints of hybrid bridges," $J$. Bridge Eng., vol. 22, no. 4, pp. 1-15, Apr 2017, http://dx.doi.org/10.1061/(ASCE)BE.1943-5592.0001020.

[13] S. Zheng, Y. Liu, T. Yoda, and W. Lin, "Parametric study on shear capacity of circular-hole and long-hole perfobond shear connector," J. Construct. Steel Res., vol. 117, pp. 64-80, Feb 2016, http://dx.doi.org/10.1016/j.jcsr.2015.09.012.

[14] E. C. Oguejiofor and M. U. Hosain, "Numerical analysis of push-out specimens with perfobond rib connectors," Comput. Struc., vol. 62, no. 4, pp. 617-624, Feb 1997, http://dx.doi.org/10.1016/S0045-7949(96)00270-2.

[15] T. Hosaka, K. Mitsuki, H. Hiragi, Y. Ushijima, Y. Tachibana, and H. Watanabe, "An experimental study on shear characteristics of perfobond strip and its rational strength equations," J. Struct. Eng., vol. 46, pp. 1593-1604, 2000.

[16] S. B. Medberry and B. M. Shahrooz, "Perfobond shear connector for composite construction," Eng. J. (N.Y.), vol. 39, no. 1, pp. 2-12, 2002.

[17] G. S. Veríssimo, "Desenvolvimento de um conector de cisalhamento em chapa dentada para estruturas mistas de aço e concreto e estudo do seu comportamento,” D.Sc. thesis, Dept. Eng. Estruturas, Univ. Fed. Minas Gerais, Belo Horizonte, 2007.

[18] S. Y. K. Al-Darzi, A. R. Chen, and Y. Q. Liu, "Finite element simulation and parametric studies of perfobond rib connector," Am. J. Appl. Sci., vol. 4, no. 3, pp. 122-127, Mar 2007.

[19] J. H. Ahn, C. G. Lee, J. H. Won, and S. H. Kim, "Shear resistance of the perfobond-rib shear connector depending on concrete strength and rib arrangement," J. Construct. Steel Res., vol. 66, no. 10, pp. 1295-1307, Oct 2010, http://dx.doi.org/10.1016/j.jcsr.2010.04.008.

[20] C. Zhao and Y. Q. Liu, "Experimental study of shear capacity of perfobond connector," Eng. Mech., vol. 29, no. 12, pp. 349-354, 2012.

[21] M. Braun, "Investigation of the load-bearing behavior of CoSFB-dowels," Ph.D. dissertation, Fac. Sci. Technol. Commun., Univ. Luxembourg, Luxembourg, 2018.

[22] C. T. Tam, S. B. Daneti, and W. Li, "EN 206 conformity testing for concrete strength in compression," Procedia Eng., vol. 171, pp. 227-237, 2017, http://dx.doi.org/10.1016/j.proeng.2017.01.330.

Author contributions: Otávio Prates Aguiar was the idealizer of this paper and contributed to the conclusions and translation of the text; Larice Gomes Justino Miranda developed the study and wrote the paper; Paulo Estevão Carvalho Silvério assisted in obtaining literature test data. All work was supervised and reviewed by Rodrigo Barreto Caldas.

Editors: Leandro Trautwein, Guilherme Aris Parsekian. 